\title{
Analysis of copepod fecal pellet carbon using a high temperature combustion method
}

\author{
Juanita Urban-Rich ${ }^{1, *}$, Dennis A. Hansell ${ }^{2}$, Michael R. Roman ${ }^{1}$ \\ ${ }^{1}$ Horn Point Laboratory, Center for Environmental Science, PO Box 775, Cambridge, Maryland 21613-0775, USA \\ ${ }^{2}$ Bermuda Biological Station for Research, Ferry Reach, St. George's, Bermuda, GE-01
}

\begin{abstract}
Copepod fecal pellet carbon was measured using a high temperature combustion (HTC) method that permitted the analysis of individual pellets. Fecal pellets were directly injected into the HTC system along with either 50 or $100 \mu l$ of low dissolved organic carbon seawater. The standard deviation around seawater blanks was $<5 \%$ of the total organic carbon content of the fecal pellets. In comparison, the standard deviation around blanks for the 'traditional' CHN analysis method was 12 to $25 \%$ of the fecal pellet carbon. Therefore, the HTC method offers less uncertainty in the measurement. Rapid freezing of fecal pellets for storage did not affect the carbon/volume relationships (i.e. slope or the $y$-intercept of the regression line between pellet carbon and volume). At a fixed chlorophyll concentration $\left(0.6 \mathrm{~g} \mathrm{fl}^{-1}\right)$ in a laboratory culture, the carbon/volume ratio (slope of the regression line) was the same regardless of the type of phytoplankton fed to the copepods. The carbon/volume ratio of the copepod pellets increased approximately linearly with increasing chlorophyll concentration, indicating that changes in food concentration affected the rate of change in carbon per unit volume of the fecal pellets. The $y$-intercept was not significantly different from zero for all diets in the laboratory studies This result suggests that changing between diatom diets (Phaeodactylum tricornutum or Thalassiosira weissflogii) and a chlorophyte diet (Dunaliella tertiolecta) did not significantly affect the carbon concentration per unit volume within fecal pellets and that the method was adequately correcting for blank errors. Copepod fecal pellets were also collected as part of the U.S. JGOFS Arabian Sea study during March-April 1995 and were analyzed with the HTC method. In the field study, there was a significant difference in carbon content per unit volume among the different pellet colors (food types). These differences between laboratory and field results may be due either to zooplankton species differences or to a heterotrophic diet in the field. The slope of the carbon/volume regression line was similar for all pellet types yet the concentration of carbon in the pellets varied in the field study. The ficld results suggest that a constant carbon/volume value cannot be used for fecal pellets to calculate their potential particulate organic carbon flux.
\end{abstract}

KEY WORDS: Copepod Fecal pellet · Carbon - High temperature combustion method

\section{INTRODUCTION}

Over the past decade many oceanographic research programs have focused on measuring and modeling carbon budgets on both local and global scales in order to better understand the oceans' capacity to store carbon. Storage of carbon occurs through the removal of organic and inorganic carbon from surface water to deep water and the sediments. Macrozooplankton fecal pellets have long been considered important in

- Present address: LUMCON, 8124 Highway 56. Chauvin, Louisıana 70344, USA. E-mail: jurban@lumcon.edu the flux of organic carbon from surface waters (Angel 1984, Noji 1991). Fecal pellet contribution to sediment trap particulate organic carbon (POC) has been found to range from $<1 \%$ (Small \& Ellis 1992, Lane et al. 1994) to $100 \%$ (Urrère \& Knauer 1981, von Bodungen et al. 1987, Urban-Rich unpubl. data) of total POC flux. An accurate measure of the carbon content of zooplankton fecal pellets is needed to correctly assess the vertical carbon flux that is due to pellets.

The amount of organic carbon in fecal pellets is influenced by the rate of pellet production along with the quality of the ingested seston (Penry \& Jumars 1986 Morales 1987). Increasing the food quality and/or the 
quantity of seston available can result in higher rates of ingestion and defecation (Dagg \& Walser 1986, Ayukai 1990). Laboratory studies have found that changes in the concentration of a phytoplankton diet do not affect the carbon:nitrogen ratio in fecal pellets (Morales 1987) yet a wide range of carbon concentrations in fecal pellets is reported for laboratory and field studies (Johannes \& Satomi 1966, Honjo \& Roman 1978, Turner 1979. Small et al. 1983, Abou Debs 1984, Tanoue \& Hara 1986, Morales 1987, Roy \& Poulet 1990, Butler \& Dam 1994). The variation in carbon content may be due to diet or to differences in zooplankton species. Fecal pellet carbon content changes over the course of a phytoplankton bloom due to differences in the organic composition of the plankton, i.e. quality of the ingested food (Butler \& Dam 1994). Changes in the assimilation efficiency due to the amount and type of food ingested (Landry et al. 1984, Hassett \& Landry 1988) may also affect the organic carbon content of fecal pellets.

The primary objective of this study was to measure the organic carbon concentration in copepod fecal pellets using a high temperature combustion (HTC) method. The second goal was to investigate the effect that different food types or concentrations had on the carbon concentration of pellets from a heterogenous community of copepods. Previous methods for measuring pellet carbon (i.e. the CHN analyzer and the atomic absorption spectrometer) require large numbers (100 to 1000) of fecal pellets to obtain sample measurements significantly above blank values. The most routinely used method involves analyzing samples in CHN systems, which normally have a 2 to $10 \mu \mathrm{g}$ carbon detection limitation. Obtaining an accurate carbon measurement on field produced pellets from a community of zooplankton has been difficult due to the large number of pellets required for analysis and the heterogeneity found in the zooplankton community. Cleanly separating the fecal pellets from the surrounding detritus and phytoplankton is difficult and time consuming at sea and this source of contamination has probably provided overestimates of fecal pellet carbon values. The CHN method gives an average pellet carbon value for the community of zooplankton present unless individual species are picked out and incubated separately. The HTC method used in this study permitted the analysis of individual fecal pellets both in the laboratory and at sea. This flexibity in analysis reduced the time required to collect samples and allowed us to the examine the effect of small changes in diet on pellet carbon/volume ratios for a heterogenous group of copepods. It was also possible to investigate the span of pellet carbon concentrations found in a natural community of zooplankton ranging from carnivores to omnivores and herbivores. A heterogenous community of copepods $>500 \mu \mathrm{m}$ was used to produce the pellets analyzed in these studies. In the study conducted in Bermuda, Oncaea spp., Eucalanus spp., Pleuromamma spp. and Microsetella spp. were the primary copepods while in the Arabian Sea Eucheata spp., Undinula spp., Oncaea spp., Oithona spp. and Eucalanus spp. were the dominant large copepods.

\section{METHODS}

High temperature combustion method for carbon analysis in fecal pellets. Laboratory experiments were conducted at the Bermuda Biological Station for Research, in May 1996. Copepods were collected near the shelf edge in $200 \mathrm{~m}$ of water with hand hauled net tows $(183 \mu \mathrm{m}$ mesh size) in the upper $20 \mathrm{~m}$. The copepods were size fractioned at the laboratory by gently wet-sieving net contents through a $500 \mu \mathrm{m}$ Nitex screen. Retained copepods were placed into four 11 plastic beakers with $500 \mu \mathrm{m}$ Nitex screening on the bottom, at a concentration of 10 copepods $1^{-1}$. The beakers containing the copepods were each placed into a second $1 \mathrm{l}$. beaker to collect the fecal pellets that fell through the Nitex screening. The beakers were filled with $10 \mu \mathrm{m}$ filtered seawater. Seven different diets involving diatoms (Phaeodactylum tricornutum and Thalassiosira weissflogii) and a chlorophyte (Dunaliella tertiolecta) were offered to the copepods over $4 \mathrm{~d}$ (Table 1). Cultures of $P$. tricornutum, D. tertiolecta or a mixture of the 2 phytoplankton were fed to the copepods at a concentration of 0.6 or $1.6 \mu \mathrm{g}$ chl $\mathrm{I}^{-1}$ $T$. weissflogii was added at a concentration of $0.8 \mu \mathrm{g}$ $\mathrm{chl} \mathrm{l}^{-1}$ or a mixture of diatoms was added at a concentration of 2.4 or $2.2 \mu \mathrm{g} \mathrm{chl} \mathrm{^{-1 }}$. The beakers containing the copepods were placed in running seawater tanks to maintain a temperature of $19 \pm 2^{\circ} \mathrm{C}$. The seawater and phytoplankton medium were exchanged every 6 h to maintain a uniform food supply. This was accomplished by transferring the insert containing the copepods to a new beaker containing fresh seawater and phytoplankton. Fecal pellets were collected in the morning, 1 h after transferring the copepods to new phytoplankton medium, to ensure the collection and analysis of freshly egested fecal pellets. Chlorophyll concentrations were measured by filtering $100 \mathrm{ml}$ of the phytoplankton medium onto a Whatman GF/F filter and extracting the sample in $90 \%$ acetone at $-20^{\circ} \mathrm{C}$ for $24 \mathrm{~h}$. Chlorophyll concentrations in the sample were measured on a Turner design fluorometer.

Fecal pellets were first sorted and separated from surrounding detritus and phytoplankton and then rinsed with deep Sargasso Sea water $(2000 \mathrm{~m})$. Each day, 20 to 30 individual fecal pellets were measured using an ocular micrometer and the volume calculated 
Table 1. Effect of food concentration and food type on the carbon/volume relationship in copepod fecal pellets as measured with a high temperature combustion (HTC) method. The $y$-variable in the regression was fecal pellet carbon (ng $C$ pellet ${ }^{-1}$ ) while the $x$-variable was fecal pellet volume $\left(\mu \mathrm{m}^{3}\right)$. The carbon/volume ratio is equal to the slope of the regression line and the $y$-intercept for all diets was not significantly different from zero in this study $(p>0.1)$

\begin{tabular}{|c|c|c|c|c|c|}
\hline Diet & $\begin{array}{c}\text { Chl } \\
\left(\mu g l^{-1}\right)\end{array}$ & $\begin{array}{l}\text { Carbon/volume ratio } \\
\text { (slope } \pm \text { S.E.) }\end{array}$ & $\begin{array}{c}y \text {-intercept } \\
\pm S E\end{array}$ & $\mathrm{n}$ & $r^{2}$ \\
\hline Dunaliella tertiolecta & 0.6 & $4.0 \pm 0.6$ & $1.5 \pm 2.1$ & 18 & 0.73 \\
\hline Phaeodactylum tricornutum & 0.6 & $3.8 \pm 0.5$ & $5.2 \pm 6.1$ & 20 & 0.62 \\
\hline 2:1 D. tertiolecta: $P$ tricornutum & 0.6 & $4.7 \pm 0.5$ & $-2.2 \pm 3.3$ & 21 & 0.84 \\
\hline Thalassiosira weissflogii & 0.8 & $3.2 \pm 0.4$ & $2.2 \pm 2.5$ & 15 & 0.82 \\
\hline P. tricornutum & 1.6 & $6.1 \pm 0.3$ & $1.0 \pm 4.4$ & 17 & 0.93 \\
\hline $1: 1 T$ weissflogii $P$ tricornutum & 2.4 & $8.4+0.7$ & $-6.7 \pm 8.4$ & 24 & 0.95 \\
\hline 1:1 T weissflogii: $P$. tricornutum & 2.2 & $8.1 \pm 0.6$ & $-5.5 \pm 6.1$ & 19 & 0.95 \\
\hline
\end{tabular}

assuming a cylindrical shape. The pellets were transferred by Pasteur pipette to separate, $7 \mathrm{ml}$ combusted scintillation vials containing $2 \mathrm{ml}$ of deep Sargasso Sea water. The vials containing the fecal pellets were refrigerated or maintained on ice until the pellets could be injected into a HTC system described by Hansell \& Waterhouse (1997; maximum length of time until injection was $6 \mathrm{~h}$ ). A corresponding 20 to 30 vials containing measured fecal pellets were 'rapidly' frozen in $0.2 \mu \mathrm{m}$ filtered seawater and then thawed and analyzed 3 to 5 d later to determine the effect of freezing on carbon concentrations and volume measurements. The rapid freeze method involves placing the scintillation vials containing the fecal pellets into an anodized aluminum block that is frozen in seawater. This cooled block supercools the seawater and fecal pellets, causing them to freeze within a minute. The rapid freezing of the seawater and fecal pellets prevents bacterial degradation of the pellet and peritrophic membrane and it reduces the chance of ice crystals forming within the pellet which could break the peritrophic membrane surrounding the pellet. After thawing, the pellets were examined microscopically and observed to be intact with no obvious tears in the peritrophic membrane.

Immediately prior to injection, the fresh fecal pellets were transferred to seawater that was acidified and sparged with $\mathrm{CO}_{2}$-free oxygen to remove inorganic carbon. Four replicates of 50 or $100 \mu$ lof the water from the vial with the fecal pellet were injected to determine background total organic carbon (TOC) concentrations. The fecal pellet was then drawn up in 50 or 100 $\mu \mathrm{l}$ of water and injected. This injection was followed by several more blank injections to ensure that there was no carry over of TOC from the pellet. Fecal pellet TOC concentrations were determined by subtracting the mean background TOC value and converting to nanograms carbon per pellet using a standard calibration curve determined daily with glucose (Hansell \& Waterhouse 1997). The volume of water used for the injections, 50 or $100 \mu l$, was determined by the size of the fecal pellet. When possible $100 \mu \mathrm{l}$ was used as this gave a more consistent background blank. For smaller fecal pellets $\left(<1 \times 10^{6} \mu^{3}\right), 50 \mu$ l was needed to obtain a carbon signal that was significantly higher than blank values (i.e. 2 times higher than the coefficient of variation around the blank). The frozen fecal pellets were thawed at room temperature and remeasured using an ocular micrometer. They were then transferred to clean, combusted $7 \mathrm{ml}$ scintillation vials with $3 \mathrm{ml}$ of deep Sargasso Sea water and treated in the same manner as the fresh pellets.

Fecal pellets collected in the Arabian Sea. Fecal pellets were collected in the Arabian Sea as part of the U.S. Joint Global Ocean Flux Study (JGOFS) in March--April 1995 aboard the RV 'Thomas G. Thompson'. Vertical net tows were conducted through the upper $60 \mathrm{~m}$ with a $1 \mathrm{~m}$ diameter, $183 \mu \mathrm{m}$ mesh net with a closed cod end. Cod end contents were gently wetsieved through 1000 and $500 \mu \mathrm{m}$ Nitex screening to obtain 2 size fractions of copepods. Copepods were incubated on deck for 2 to $3 \mathrm{~h}$ in $20 \mathrm{l}$ of euphotic zone seawater. The fecal pellets were picked out under a dissecting microscope, separated by color and rinsed with $0.2 \mu \mathrm{m}$ filtered seawater. They were then rapidly frozen in $5 \mathrm{ml}$ of $0.2 \mu \mathrm{m}$ filtered seawater at $-70^{\circ} \mathrm{C}$ in the same manner as described previously. Fecal pellets were collected at 3 stations located at $15^{\circ} \mathrm{N}, 63^{\circ} \mathrm{E}$, $16^{\circ} \mathrm{N}, 61^{\circ} \mathrm{E}$, and $17^{\circ} \mathrm{N}, 59^{\circ} \mathrm{E}$. The fecal pellet samples were transported frozen to Bermuda, where they were thawed, measured with an ocular micrometer and analyzed as previously described.

Simultaneous to the collection of these samples, fecal pellets were collected for traditional CHN analysis. For these measurements, 100 to 150 fecal pellets were picked out under the microscope, rinsed with $0.2 \mu \mathrm{m}$ filtered seawater and filtered onto a combusted $13 \mathrm{~mm}$ Gelman A/E glass fiber filter placed on top of a backing filter. Both filters were immediately dried at $60^{\circ} \mathrm{C}$ and returned to Horn Point Environmental Laboratory, where they were analyzed with a Control Systems 
CHN analyzer. The values determined for the backing filters were subtracted from the sample filters to correct for filter and machine blank. To obtain an average carbon/pellet concentration the total number of fecal pellets filtered was divided into the total carbon measured on the filter.

\section{RESULTS}

\section{Fecal pellet carbon analysis}

The high temperature combustion (HTC) method used in this study permitted the analysis of carbon concentrations in individual fecal pellets. Fecal pellet carbon values were 1.25 to $3 \times$ higher than seawater concentrations alone. Blank values were consistent within one run, and between runs the coefficient of variation was only 3 to $6 \%$ (Table 2). Both within one run, i.e. the blank seawater and fecal pellet injection, and between samples the standard deviations around the blank concentrations in the HTC method were $<5 \%$ of fecal pellet carbon concentrations. This permitted a fairly reliable and consistent estimate of fecal pellet carbon. In comparison, the blanks for the samples run on the CHN analyzer ranged from 13 to $75 \%$ of the carbon load on the sample filters and were not consistent between samples (coefficient of variation $=43$ to $61 \%$; Table 2), indicating that blank backing filters must be taken with each sample. The standard deviation of the blanks was 12 to $25 \%$ of the estimated fecal pellet carbon. Comparison of the fecal pellet carbon estimates from CHN analysis with an average value from the HTC method revealed no significant difference between the 2 methods for the mean carbon/pellet concentrations from the different stations (Wilcoxon's paired $t$-test: $t=-0.68$, critical $t=2.35, \alpha=0.05$ ) and the coefficients of variation were similar for each method (Table 2). However, the advantages of the HTC method over the traditional C.HN method are that it provides additional information on the range and variability that occur in one CHN sample, it is easier and faster to use in the field and it gives additional information about pellet carbon/volume ratios and pellet carbon concentrations for different food types.

Sample collection and storage are important factors in terms of the usefulness of a method in the field. During the laboratory study conducted at the Bermuda Biological Station for Research, the effects of rapid freezing on fecal. pellet volumes and pellet carbon concentrations were examined. Freezing the fecal pellets could potentially change both the pellet volume and the carbon concentration if the peritrophic membrane surrounding the pellets is ruptured. Rupture of the membrane would lead to the pellets expanding, i.e. increasing their volume, and it would also permit a rapid release of dissolved organic carbon from the pellets and possibly the loss of small particulate fractions from the pellets, thereby decreasing the carbon content of the pellets. The copepods were fed a diet of either Thalassiosira weissflogii or Dunaliella tertiolecta to determine if food type affected the results of freezing on pellet volume and carbon concentration. A paired t-test showed no significant difference in the measured volumes of the fecal pellets before or after being thawed ( $p=0.260$, $T$. weissflogii; $\mathrm{p}=0.074, D$. tertiolecta). To determine if rapid freezing of the pellets affected the carbon content, the slope homogeneity for fresh and frozen fecal pellet was examined using an ANCOVA. For both food types no significant differences were found in the slopes of the carbon/volume regression lines for either fresh or rapidly frozen fecal pellets ( $T$ weissflogii, $\mathrm{p}=$ $0.570 ; D$. tertiolecta, $p=0.628$; Figs. $1 \& 2$ ). A lack of significant treatment (fresh vs frozen) effects for both diets

Table 2. Comparison of average fecal pellet carbon content between CHN and HTC analysis for fecal pellets collected in the Arabian Sea (mean \pm SD). Average fecal pellet carbon concentrations determined from CHN analysis, corrected for the number of fecal pellets filtered on each sample filter and the blank filter, are calculated from 3 samples (each sample consisted of 100 fecal pellets) and the average HTC values are calculated from 100 individual pellet measurements that were corrected for blank values. Average blank values for the CHN analysis were determined from blank backing filters and for the HTC analysis from seawater injections (mean $\pm \mathrm{SD}, \mathrm{n}=3$ for the CHN measurements, $\mathrm{n}=100$ for the HTC measurements). \% CV: coefficient of variation

\begin{tabular}{|c|c|c|c|c|c|c|c|c|}
\hline Stn & $\begin{array}{l}\text { CHN pellet } \\
\text { carbon } \\
\text { (ng C pellet }{ }^{-1} \\
\pm \text { SD) }\end{array}$ & $\begin{array}{c}\% \text { CV CHN } \\
\text { pellet } \\
\text { carbon }\end{array}$ & $\begin{array}{l}\text { CHN blank } \\
\text { (ng C pellet }^{-1} \\
\pm \text { SD) }\end{array}$ & $\begin{array}{l}\% \text { CV CHN } \\
\text { blank }\end{array}$ & $\begin{array}{c}\text { HTC pellet } \\
\text { carbon } \\
\text { (ng C pellet }{ }^{-1} \\
\pm S D)\end{array}$ & $\begin{array}{c}\% \text { CVHTC } \\
\text { pellet } \\
\text { carbon }\end{array}$ & $\begin{array}{c}\text { HTC blank } \\
\text { (ng C } \\
100 \mu \mathrm{l}^{-1} \\
\pm \mathrm{SD})\end{array}$ & $\begin{array}{c}\% \text { CV HTC } \\
\text { blank }\end{array}$ \\
\hline $15^{\circ} \mathrm{N}, 63^{\circ} \mathrm{E}$ & $47 \pm 21$ & 45 & $1316 \pm 564$ & 43 & $48 \pm 28$ & 58 & $31 \pm 2$ & 6 \\
\hline $16^{\circ} \mathrm{N}, 61^{\circ} \mathrm{E}$ & $44 \pm 36$ & 82 & $2306 \pm 1100$ & 48 & $81 \pm 73$ & 90 & $46 \pm 2$ & 4 \\
\hline $17^{\circ} \mathrm{N}, 59^{\circ} \mathrm{E}$ & $131 \pm 98$ & 75 & $4091 \pm 2489$ & 61 & $27 \pm 9^{a}$ & 33 & $38 \pm 1^{\circ}$ & 3 \\
\hline Average & $74 \pm 40$ & 54 & $2590 \pm 1332$ & 51 & $52 \pm 22$ & 42 & $33 \pm 2$ & 6 \\
\hline
\end{tabular}




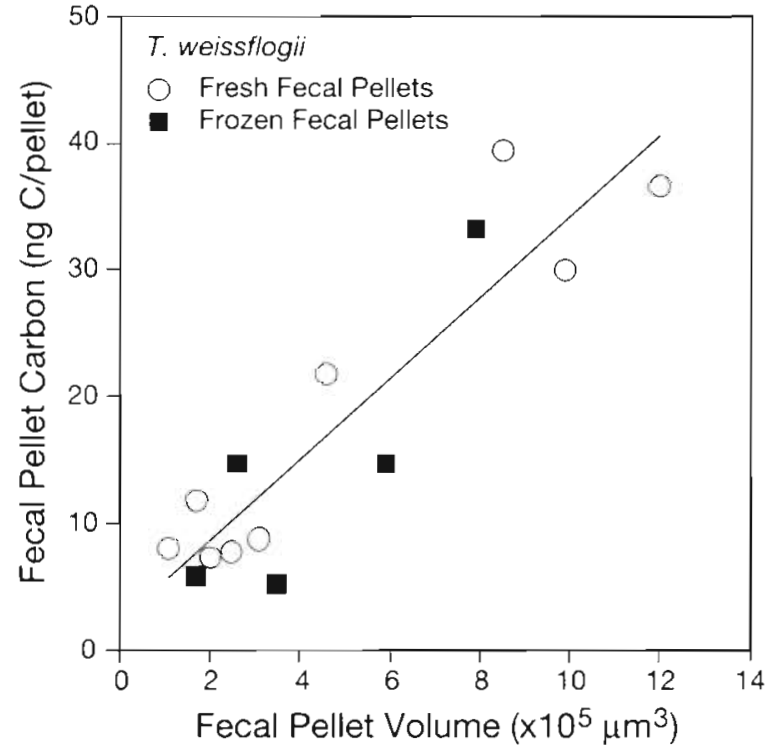

Fig. 1. Macrozooplankton fecal pellet carbon concentration, as determined using a high temperature combustion method, versus fecal pellet volume for pellets produced on a diet of Thalassiosira weissflogii. The common regression line is shown because the fresh and frozen fecal pellets could be grouped together (slopes of the regression lines for the 2 treatments were not significantly different, $p=0.570$ ). Fresh fecal pellets: $y=3.66 x+3.04, n=10, r^{2}=0.86$; frozen fecal pellets: $y=-1.59 x+3.77, n=10, r^{2}=0.72$

indicated that rapid freezing is a viable means of storing pellets for later analysis.

\section{Effect of diet on fecal pellet carbon/volume ratio}

The usefulness of this HTC method compared to the CHN method is demonstrated in the laboratory studies. These experiments examined the effects of different food types and food concentrations on fecal pellet carbon to volume relationships. In this paper, we have defined the terms carbon/volume relationship to mean the analysis of the slope of the carbon/volume regression line along with the $y$-intercept while the carbon/ volume ratio refers to an analysis of only the slope of the regression line. The effects of different food types and concentrations were examined by feeding several phytoplankton species to the copepods both in monocultures and in mixtures. Significant correlations were found between pellet carbon and volume for all the diets offered to the copepods (Table 1). The effect of different food types on the carbon/volume relationship (i.e. slope of the regression line and the $y$-intercept) was examined by feeding the copepods a monoculture of either Dunaliella tertiolecta or Phaeodactylum tricornutum or a 2:1 mixture of $D$. tertiolecta: $P$. tricornu-

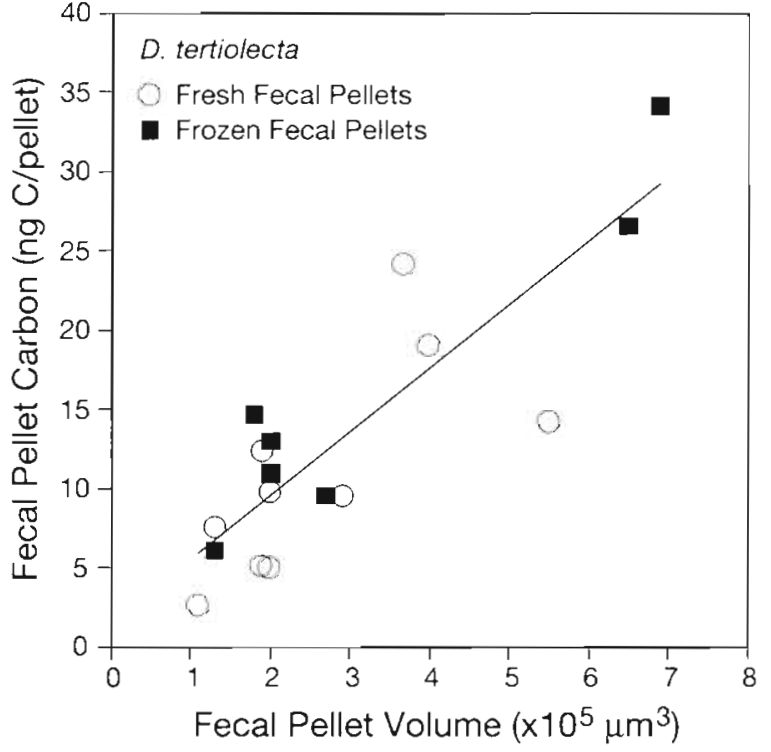

Fig. 2. Macrozooplankton fecal pellet carbon concentration, as measured using a high temperature combustion method, versus fecal pellet volume for copepods fed on a diet of Dunaliella tertiolecta. The common regression line for the fresh and frozen fecal pellets is shown because the data could be grouped together (no significant difference was found between the slopes for the 2 treatments $p=0.628$ ). Fresh fecal pellets: $y=4.08 x+2.85, n=10, r^{2}=0.90$; frozen fecal pellets: $y=3.42 x+1.92, n=10, r^{2}=0.60$

tum at a uniform chlorophyll concentration of $0.6 \mu \mathrm{g}$ $\mathrm{l}^{-1}$. ANCOVA indicated that there were no differences between the slopes of the carbon/volume regression lines for any of the diets, indicating that for a given chlorophyll concentration the carbon/volume ratio (i.e. slope of the carbon/volume regression line) remained the same (Table 1) and the $y$-intercept was not significantly different from zero. These results suggest that these limited diets, and possibly any autotrophic food supply, do not affect the pellet carbon/volume relationship for a community of zooplankton.

A second set of 2 experiments was conducted to determine if changing the chlorophyll concentration along with changing the food type would affect the fecal pellet carbon/volume relationships. In the first experiment the copepods were divided into 3 groups and fed different diatom diets. A third of the copepods were fed Thalassiosira weissflogii at $0.8 \mu^{-1}$, a third of the copepods were fed Phaeodactylum tricornutum at $1.6 \mathrm{pg} \mathrm{l}^{-1}$ and the remaining copepods were fed a 1:1 mixture of $T$. weissflogii: $P$. tricornutum at $2.4 \mu \mathrm{g} \mathrm{l}^{-1}$. Examining the slope between pellet carbon and volume for each diet revealed that changes in the chlorophyll concentration significantly affected the pellet carbon/volume ratio ( $\mathrm{p}=0.004$; Table 1$)$. These differences do not appear to be due to the different diatoms 


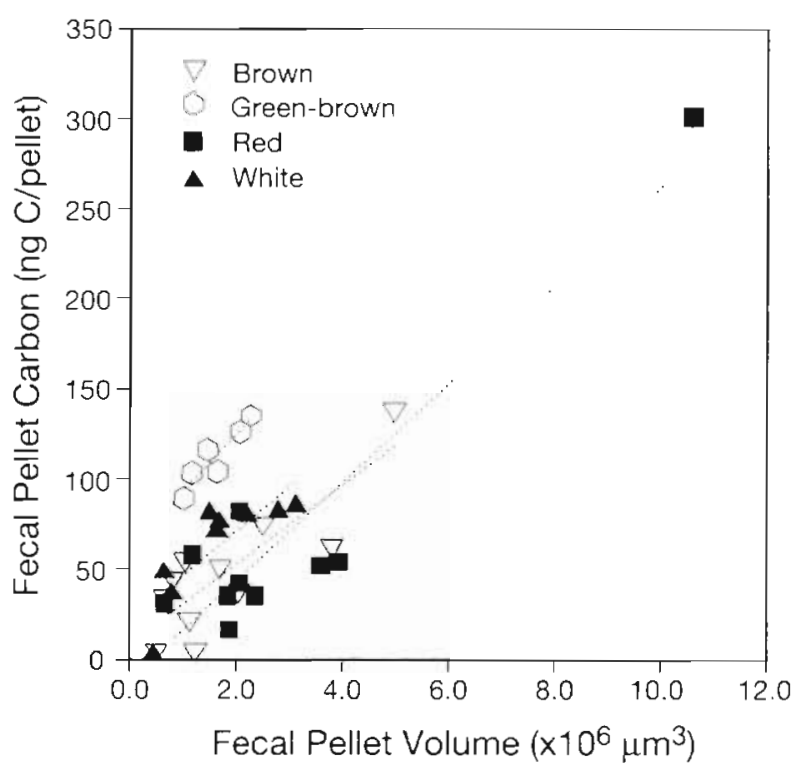

Fig. 3. Relationships between fecal pellet carbon concentration and pellet volume for field produced fecal pellets. The fecal pellets were collected from a community of zooplankton fed naturally occurring seston in the Arabian Sea. The fecal pellets were sorted by color, with this serving as a proxy for diet: brown, most likely containing a mixture of autotrophic and heterotrophic plankton; green-brown, probably com-

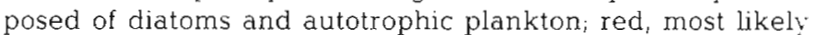
produced by carnivorous zooplankton (the highest carbon' volume data point is not included in the actual statistics) white, presumably formed through coprophagy or the ingestion of detritus or flagellates

fed to the copepods as the carbon/volume ratios (slope) for copepods fed $P$, tricornutum at $0.6 \mu \mathrm{g} \mathrm{I}^{-1}$ and for copepods fed $T$. weissflogii at $0.8 \mu \mathrm{g} \mathrm{l}^{-1}$ were not significantly different $(p=0.246$; Table 1$)$; however, the slope of the carbon/volume regression line for copepods fed $P$. tricornutum at $1.6 \mathrm{~g} \mathrm{l}^{-1}$ was significantly different $(p=0.008)$. In the second experiment conducted a day later, half the copepods were fed a $1: 1$ mixture of $T$. weissflogii: $P$. tricornutum at $2.2 \mu \mathrm{g} \mathrm{I}^{-1}$ and the other copepods were fed a $2: 1$ mixture of Dunaliella tertiolecta: $P$. tricornutum at $0.6 \mathrm{mg}^{-1}$. Sig- nificantly different carbon/volume ratios $(p<0.001)$ were found for the 2 diets, indicating that chlorophyll concentrations can affect the carbon/volume ratio (i.e. the rate of change in carbon per unit volume) yet the $y$-intercepts were not significantly different from each other or from zero (Table 1). In both experiments the treatments with the higher chlorophyll concentration resulted in a higher carbon/volume ratio (i.e. slope of the regression line; Table 1 ).

\section{Carbon/volume of field collected fecal pellets}

The fecal pellets that were collected at $15^{\circ} \mathrm{N}, 63^{\circ} \mathrm{E}$ in the Arabian Sea were produced on a naturally occurring seston and were from 2 different size classes of copepods, 500-1000 and >1000 $\mu \mathrm{m}$. Analysis of the data by zooplankton size class revealed no significant correlation between pellet carbon and volume for either size class ( $p>0.05$ ). Experiments to produce and collect fecal pellets from copepods $>500 \mu \mathrm{m}$ were also conducted at $16^{\circ} \mathrm{N}, 61^{\circ} \mathrm{E}$ and $17^{\circ} \mathrm{N}, 59^{\circ} \mathrm{E}$. The $3 \mathrm{sta}-$ tions ranged from an offshore oligotrophic site to a near-shore eutrophic site. Zooplankton biomass and species composition also varied between the 3 stations (Roman unpubl. data). The data from the 3 stations were compared to determine if there were any correlations between pellet carbon and volume by station. No significant correlations were found within stations or by pooling all the data ( $p>0.05$ in all cases).

During the collection and preservation of the fecal pellets on board ship, they were first sorted by color as a proxy for zooplankton diet. The pellets were sorted into different color categories: green-brown, most likely composed of diatoms and autotrophic protists; brown, most likely composed of mixture of heterotrophic and autotrophic plankton; red, most likely produced by carnivorous zooplankton; and white, most likely formed from coprophagy or the consumption of detritus or flagellates. Significant correlations were found between carbon concentration and volume when the data was analyzed by pellet color (Fig. 3, Table 3).

Table 3. Carbon/volume relationships based on fecal pellet color for pellets collected in the Arabian Sea in March-A.pril 1995 and measured with a HTC method. The carbon (ng C pellet $\left.{ }^{-1}\right) /$ volume $\left(\times 10^{\mathrm{b}} \mathrm{\mu m}^{3}\right)$ ratio is equal to the slope of the regression lune

\begin{tabular}{|c|c|c|c|c|c|}
\hline Fecal pellet color & $\begin{array}{l}\text { Carbon/volume ratio } \\
\text { (slope } \pm \text { SE) }\end{array}$ & $\begin{array}{l}y \text {-intercept } \\
\quad \pm \mathrm{SE}\end{array}$ & $\mathrm{n}$ & $\mathrm{p}$ & $r^{2}$ \\
\hline Brown & $21 \pm 4$ & $12 \pm 10$ & 10 & 0.001 & 0.74 \\
\hline Green-brown & $32 \pm 7$ & $61 \pm 11$ & 6 & 0.008 & 0.86 \\
\hline $\operatorname{Red}^{a}$ & $27 \pm 4$ & $-12 \pm 15$ & 9 & 0.020 & 0.68 \\
\hline White & $25 \pm 5$ & $18 \pm 11$ & 9 & 0.002 & 0.76 \\
\hline
\end{tabular}


Data from the 3 stations were pooled and examined with an ANCOVA to determine if pellet color (i.e. food type) had a significant effect on the carbon/volume relationships. No significant difference was found between the slopes of the regression lines, indicating that the carbon/volume ratio was similar for all food types ingested $(p=0.716)$. However, a significant difference was found in the concentration of carbon per unit volume as indicated by a higher $y$-intercept for the different food types. Multiple comparison testing revealed that the green-brown fecal pellets, presumably from a diet of diatoms and autotrophic protists, had a higher carbon concentration per unit volume than the brown, red or white fecal pellets.

\section{DISCUSSION}

Accurate measurements of carbon concentrations in fecal pellets are necessary to estimate the contribution made by pellets to POC flux. The primary advantages of the HTC method are the ability to measure the carbon concentration on an individual fecal pellet and the increased ease of sample collection. Nevertheless, the average carbon concentration per pellet (determined from 100 fecal pellets) for a mixed community of copepods was not significantly different between the 2 methods and the coefficient of variation $(\mathrm{CV})$ on the average value was generally not different between the methods (CHN or HTC; Table 2). However, the HTC method allowed us to obtain data not possible with the CHN method and to obtain more accurate individual fecal pellet carbon measurements. By being able to measure the carbon concentration of individual fecal pellets, we were able to obtain the range of carbon concentrations found in fecal pellets from a natural community of copepods, examine the pellet carbon/ volume relationships and to determine the carbon concentration of pellets produced on different diets. The HTC method gave carbon values on individual fecal pellets with a small error due to little background variability, e.g. the CV on the blanks within 1 sample run was 1 to $3 \%$ and between 100 sample runs was only 3 to $6 \%$. In comparison, the CHN measurements had a much higher percent of variability around the individual fecal pellet estimates due to the high blank concentrations and blank variability (CV on 3 blanks was 43 to $61 \%$ ). The HTC method also allowed us to take the measurements in near real time at sea and in the laboratory, thereby eliminating any error associated with sample storage.

The increased sensitivity found with the HTC method should permit investigators to expand their studies to examine the contribution to pellet carbon flux made by different zooplankton species through- out the water column and in different water masses. This should lead to more accurate estimates of fecal pellet carbon flux. In this study we incubated a community of copepods rather than sorted and separated species. There are pros and cons to both the community and species approach with zooplankton incubations. Using the total zooplankton community along with the HTC method allowed us to easily measure the natural range of fecal pellet carbon concentrations produced in the water column and how changes in diet affected the total community's fecal pellet carbon concentrations. Also, analysis of fecal pellets from the Arabian Sea showed that different feeding modes could be detected with the HTC method, i.e. correlations between carbon and volume based on pellet color. However, using the HTC method with the species approach should give added insight into the role of different copepods in carbon cycling. A limiting factor with the species approach has been the sampling time and quantity of pellets required to get a good average carbon value. The decreased sampling time and number of pellets required with the HTC method could allow investigators to do detailed studies on all the major mesozooplankton in an area rather than on just 1 or 2 species.

Examining the processes that affect pellet carbon content along with coprophagy and carbon decay is important for understanding and predicting the POC flux in the ocean. One of the factors that can strongly influence fecal pellet carbon content is the amount, type and quality of food ingested. Changes in zooplankton food web structure occur over a seasonal scale based on available and ingested seston (Urban et al. 1992). These changes in ingested seston from diatoms to heterotrophic flagellates along with changes in the quality of seston over the course of a bloom affect pellet carbon flux. Coprophagy, the consumption of fecal pellets by copepods, is a poorly understood process. Relatively little is known about the degree to which coprophagy occurs in the open ocean and how this process influences the amount and quality of carbon found in the fecal pellets. Being able to analyze single pellets with the HTC method should permit investigations of the amount of organic carbon present in fecal pellets produced via coprophagy, as obtaining large samples with this type of feeding is difficult. Additionally, the HTC method should allow investigators to examine more accurately the rates and kinetics of carbon decay in pellets. Previous studies have exam. ined carbon loss from fecal pellets by incubating 100 to 200 pellets in a small volume of water (Honjo \& Roman 1978, Turner 1979, Roy \& Poulet 1990). In these studies, carbon decay may have been more representative of what occurs in an aggregate rather than in an individual fecal pellet settling through the water column. 
Another important factor in determining the usefulness of a method is the time required to collect the samples and prepare them for analysis. The $\mathrm{CHN}$ method requires 100 to 150 fecal pellets per sample, which means either long incubations or the collection of large numbers of copepods plus 0.5 to $2 \mathrm{~h}$ to pick and clean the pellets for filtering. All of these factors could result in pellet decay and smaller carbon concentrations by the time the samples are actually collected and analyzed. The ability of the HTC method to measure individual fecal pellets means that experiments and collection time of samples can be short. Freezing the fecal pellets permits samples to be collected quickly and easily at sea and then analyzed at a more convenient time in the laboratory. Also, being able to analyze single fecal pellets should allow investigators to design more accurate experiments, i.e. in terms of time and number of copepods per volume of water. This ability with the HTC method to have 'natural' experiments along with a short turnaround time for sample collection and analysis is essential in tropical locations, where the decay rate of fecal pellets is on the scale of hours (Honjo \& Roman 1978).

Direct and estimated measurements of the carbon concentration in zooplankton fecal pellets has been found to range over 3 orders of magnitude (Table 4 and references therein). Some of the variability reported can be explained by species differences and the feeding mode of the zooplankton (e.g. filter feeding salps vs raptorial copepods). Comparing the studies on carbon/volume in Acartia spp. fecal pellets (Table 4; Honjo \& Roman 1978, Butler \& Dam 1994, Hansen et al. 1996) reveals a 10-fold range. The majority of the mea-

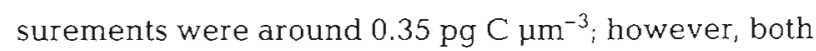
Butler \& Dam (1994) and Honjo \& Roman (1978) reported values 2 to 7 times higher. This variability is most likely due to changes in the food concentration, food quality, or errors in the measurements. Results from our studies suggest that changes in food type (green-brown pellets vs brown, red or white pellets) or food concentration can affect the carbon/volume relationships in copepod fecal pellets (Fig. 3, Table 1).

Comparing studies on carbon content in fecal pellets is difficult due to the variety of units used to express carbon concentration. Carbon content can be stated in terms of amount per pellet, per pellet volume or per dry weight. These variations in units mean that little is known about the effects of diet on carbon content of fecal pellets. Morales (1987) found that the carbon and nitrogen content of copepod fecal pellets was independent of food concentration when examined in terms of carbon or nitrogen per unit dry weight of the pellets. The quantity and quality of food are known to affect fecal pellet production rates (Ayukai 1987, Kiørboe et al. 1982, Butler \& Dam 1994), volume (Ayukai \& Nishizawa 1986, Dagg \& Walser 1986) and density (Bienfang 1980, Urban et al, 1993, Butler \& Dam 1994). In a simulated bloom study, Butler \& Dam (1994) found that changes in food quality resulted in changes in fecal pellet volume, density and carbon content, such that pellets produced during the mid-bloom would have the greatest impact on carbon flux.

Results from the present study indicate that for a given food concentration the pellet carbon/volume relationship does not change for a community of zooplankton (Table 1). Yet the type of food, autotrophic

Table 4. Zooplankton fecal pellet carbon concentrations as reported in the literature and scaled by an average volume as reported for each experiment or for the study

\begin{tabular}{|c|c|c|c|c|}
\hline Producer & Food conditions & Reported carbon & $\begin{array}{l}\text { Carbon/volume } \\
\left(\mathrm{pg} C \mu \mathrm{m}^{-3}\right)\end{array}$ & Source \\
\hline Acartia clausi & $\begin{array}{l}\text { Natural seston } \\
\left(200000 \text { cells } ~^{-1}\right)\end{array}$ & $96-187 \mathrm{ng}$ & $0.38-0.75$ & Honjo \& Roman (1978) \\
\hline $\begin{array}{l}\text { Cyclosalpa pinnata } \\
\text { Pegea socia } \\
\text { Salpa maxima }\end{array}$ & Natural seston & $\begin{array}{c}51-300 \mu \mathrm{g} \\
67-112 \mu \mathrm{g} \\
191-355 \mu \mathrm{g}\end{array}$ & $\begin{array}{l}0.002-0.016 \\
0.005-0.006 \\
0.002-0.007\end{array}$ & Madin (1982) \\
\hline Temora stylifera & Hymenomonas elongata & $154 \mathrm{ng}$ & 0.21 & Abou Debs (1984) \\
\hline $\begin{array}{l}\text { Salpa maxima } \\
\text { Pegea bicaudata }\end{array}$ & Natural seston & $\begin{array}{l}407 \mu g \\
183 \mu g\end{array}$ & $\begin{array}{l}0.01 \\
1.94\end{array}$ & Caron et al. (1989) \\
\hline Meganyctiphanes norvegica & Natural seston & $2.6-5.8 \mu \mathrm{g}$ & $0.01-0.02$ & Youngbluth et al. (1989) \\
\hline Large copepods & Natural seston & $2.4-512 \mu \mathrm{g}$ & $6.86-506.93$ & Lane et al. (1994) \\
\hline Acartia tonsa & Thalassiosira weissflogui & $1.7-25 \mu \mathrm{g} \mu \mathrm{m}^{-3} \times 10^{-7}$ & $0.17-2.5$ & Butler \& Dam (1994) \\
\hline Acartia tonsa & $\begin{array}{l}\text { Thalassiosira weissflogï } \\
\text { Rhodomonas baltica }\end{array}$ & & $\begin{array}{l}0.28 \\
0.39\end{array}$ & Hansen et al. (1996) \\
\hline Large copepods & Natural seston & $4-220 \mathrm{ng}$ & $0.01-0.06$ & Urban-Rich (1997) \\
\hline Large copepods & Natural seston & $3-325 \mathrm{ng}$ & $0.01-0.25$ & This study \\
\hline
\end{tabular}


(green-brown pellets in the Arabian Sea) versus heterotrophic (brown, red or white pellets), can result in changes in the carbon concentration per unit volume in the pellets as seen in the higher elevation ( $y$-intercept) of the regression line (Fig. 3, Table 3).

In contrast, changes in food concentration resulted in significantly different pellet carbon/volume ratios (Table 1). The result was that a doubling in chlorophyll concentration approximately doubled the slope of the carbon/volume relationship. The reason for this doubling is not known and may be due to increased packing of food items into the fecal pellet, superfluous feeding (Beklemishev 1962) or partial digestion of the food (Penry \& Jumars 1986). It was not possible in the present study to control the quality of the food, so some of the changes in carbon content may reflect changes in food quality as well as food quantity. The results from the fecal pellets collected in the Arabian Sea indicate that regardless of zooplankton size or site location a constant carbon/volume ratio (i.e. rate of change in the carbon to volume) is relevant for a given zooplankton feeding mode (Fig. 3).

Changes in fecal pellet carbon have important implications for carbon cycling in the ocean. Larger fecal pellets tend to have higher sinking velocities (Komar et al. 1981), suggesting that they will be transported to greater depths. High concentrations of food have been found to result in higher fecal pellet volumes (Dagg \& Walser 1986) and pellet production rates (Ayukai 1987 , 1990). The results from this study suggest that high. concentrations of food result in a higher carbon/volume ratio, thus potentially increasing the contribution of the fecal pellets to total POC sinking flux.

Acknowledgements. We sincerely thank Rachel Parsons, Dr Craig Carlson and Dr Debbie Steinberg at the Bermuda Biological Station for Research (BBSR) for help with the HTC method and for help in collecting zooplankton for the laboratory study. Also, we thank Dr Norm Nelson at the BBSR for providing the phytoplankton cultures. We also acknowledge the assistance of Anne Gauzens and the crew of RV 'Thomas G. Thompson' for help in collecting the zooplankton and fecal pellets during the Arabian Sea Process cruise. This work was supported by NSF grants OCE-9310687 to M.R.R. and OCE9311012 to D.A.H. This manuscript is UMCES contribution no. 3062.

\section{LITERATURE CITED}

Abou Debs C (1984) Carbon and nitrogen budget of the calanoid copepod Temora stylifera: effect of food concentration and composition of food. Mar Ecol Prog Ser 15: $213-223$

Angel MV (1984) Detrital organic fluxes through pelagic ecosystems. In: Fasham MJ (ed) Flows of energy and materials in marine ecosystems: theory and practice. Plenum Press, New York, p 475-516

Ayukai T (1987) Feeding by the planktonic calanoid copepod
Acartia clausi Giesbrecht on natural suspended particulate matter of varying quantity and quality. J Exp Mar Biol Ecol 106:137-149

Ayukai T (1990) Fecal pellet production by two species of planktonic calanoid copepods fed on naturally occurring particles. Bull Plankton Soc Jpn 37:167-169

Ayukai T, Nishizawa S (1986) Defecation rate as a possible measure of ingestion rate of Calanus pacificus pacificus (Copepoda:Calanoida). Bull Plankton Soc Jpn 33:3-10

Beklemishev CV (1962) Superfluous feeding of marine herbivorous zooplankton. Rapp PV Rèun Cons Perm Int Explor Mer 153:108-113

Bienfang PK (1980) Herbivore diet affects fecal pellet settling Can J Fish Aquat Sci 37:1352-1357

Butler M, Dam HG (1994) Production rates and characteristics of fecal pellets of the coepod Acartia tonsa under simulated phytoplankton bloom conditions: implications for vertical flux. Mar Ecol Prog Ser 114:81-91

Caron DA, Madin LP, Cole JJ (1989) Composition and degradation of salp fecal pellets: implications for vertical flux in oceanic environments. J Mar Res 47:829-850

Dagg MJ, Walser WE Jr (1986) The effect of food concentration on fecal pellet size in marine copepods. Limnol Oceanogr 31:1066-1071

Hansell DA, Waterhouse TY (1997) Controls on the distribution of organic carbon and nitrogen in the eastern Pacific Ocean. Deep-Sea Res 44:843-857

Hansen B, Fotel FL, Jensen NJ, Madsen SD (1996) Bacteria associated with a marine planktonic copepod in culture. II. Degradation of fecal pellets produced on a diatom, a nanoflagellate or a dinoflagellate diet. J Plankton Res 18 : $275-288$

Hassett RP, Landry MR (1988) Short-term changes in feeding and digestion by the copepod Calanus pacificus. Mar Biol 99:63-74

Honjo S, Roman MR (1978) Marine copepod fecal pellets: production, preservation and sedimentation. J Mar Res 36 : 45-57

Johannes RE, Satomi M (1966) Composition and nutritive value of fecal pellets of a marine crustacean. Limnol Oceanogr 11:191-197

Kiørboe T, Møhlenberg F, Nicolajsen H (1982) Ingestion rate and gut clearance in the planktonic copepod Centropages hamatus (Lilljeborg) in relation to food concentration and temperature. Ophelia 21:181-194

Komar PD, Morse AP, Small LF, Fowler SW (1981) An analysis of sinking rates of natural copepod and euphausiid fecal pellets. Limnol Oceanogr 26:172-180

Landry MR, Hassett RP, Fagerness V, Down J, Lorenzen CJ (1984) Effect of food acclimation on assimilation efficiency of Calanus pacificus. Limnol Oceanogr 29:361-364

Lane PVZ, Smith SL, Urban JL, Biscaye PE (1994) Carbon flux and recycling associated with zooplanktonic fecal pellets on the shelf of the Middle Atlantic Bight. Deep-Sea Res 41 : $437-457$

Madin LP (1982) Production, composition and sedimentation of salp fecal pellets in oceanic waters. Mar Biol 67:39-45

Morales CE (1987) Carbon and nitrogen content of copepod faecal pellets: effect of food concentration and feeding behavior. Mar Ecol Prog Ser 36:107-114

Noji TT (1991) The influence of macrozooplankton on vertical particulate flux. Sarsia $76: 1-9$

Penry DL, Jumars PA (1986) Chemical reactor analysis and optimal digestion. BioSci 36:310-315

Roy S, Poulet SA (1990) Laboratory study of the chemical composition of aging copepod fecal material. J Exp Mar Biol Ecol 135:3-18 
Small LF, Ellis SG (1992) Fecal carbon production by zooplankton in Santa Monica Basin: the effects of body size and carnivor ous feeding. Prog Oceanogr 30:197-221

Small LF, Fowler SW, Moore SA, LaRosa J (1983) Dissolved and fecal pellet carbon and nitrogen release by zooplankton in tropical waters. Deep-Sea Res 30:1199-1220

Tanoue E, Hara S (1986) Ecological implications of fecal pellets produced by the Antarctic krill Euphausia superba in the Antarctic Ocean. Mar Biol 91:359-369

Turner JT (1979) Microbial attachment to copepod fecal pellets and its possible ecological significance. Trans Am Microsc Soc 98:131-135

Urban JL, Diebel D, Schwinghamer P (1993) Seasonal variations in the densities of fecal pellets produced by Oikopleura vanhoeffeni (C. Larvacea) and Calanus finmarchicus (C. Copepoda). Mar Biol 117:607-614

Urban JL, McKenzie CH, Deibel D (1992) Seasonal differences in the content of Oikopleura vanhoeffeni and

Editorial responsibility: Kenneth Tenore (Contributing Editor), Solomons, Maryland, USA
Calanus finmarchicus faecal pellets: illustrations of zooplankton food web shifts in coastal Newfoundland waters. Mar Ecol Prog Ser 84:255-264

Urban-Rich J (1997) Latitudinal variations in copepod fecal peliet contnbution to organic carbon and amino acid flux. PhD dissertation, Unive:sity of Maryland, College Park

Urrère MA. Knauer GA (1981) Zooplankton fecal pellet fluxes and vertical transport of particulate organic material. in the pelagic environment. J Plankton Res 3:369-387

von Bodungen B, Fischer G, Nothig EM, Wefer G (1987) Sedimentation of krill faeces during spring development of phytoplankton in Bransfield Strait, Antarctica. SCOPE/ UNEP Sonderband 62:243-257

Youngbluth MJ, Bailey TG, Davoll PJ, Jacoby CA, BladesEckelbarger PI, Griswold CA (1989) Fecal pellet production and diel migratory behavior by the euphausiid Meganyctiphanes norvegica effect benthic-pelagic coupling. Deep-Sea Res 36:1491-1501

Submitted: October 18, 1997; Accepted: June 23, 1998 Proofs received from author(s): September 21, 1998 